Article

\title{
Medium Bandgap D-A Type Photovoltaic Polymers Based on an Asymmetric Dithienopyran Donor and a Benzotriazole Acceptor
}

\author{
Junyi Hu ${ }^{1,2}$, Xiaochen Wang ${ }^{1, *}$, Fan Chen ${ }^{1,2}$, Bo Xiao ${ }^{1,2}$, Ailing Tang ${ }^{1}$ and Erjun Zhou ${ }^{1, *}$ \\ 1 CAS Key Laboratory of Nanosystem and Hierarchical Fabrication, CAS Center for Excellence in \\ Nanoscience, National Center for Nanoscience and Technology, Beijing 100190, China; \\ hujy@nanoctr.cn (J.H.); chenf@nanoctr.cn (F.C.); xiaob@nanoctr.cn (B.X.); tangal@nanoctr.cn (A.T.) \\ 2 University of Chinese Academy of Sciences, Beijing 100049, China \\ * Correspondence: wangxc@nanoctr.cn (X.W.); zhouej@nanoctr.cn (E.Z.); Tel.: +86-10-8254-5531 (X.W.); \\ +86-10-8254-5699 (E.Z.)
}

Received: 20 September 2017; Accepted: 12 October 2017; Published: 17 October 2017

\begin{abstract}
Conjugated polymers based on the donor of an asymmetric $5 H$-dithieno[3,2-b:2', $3^{\prime}$-d]pyran (DTPa) and the acceptors of benzo[d][1,2,3]triazole (BTA) or di-fluorinated benzo[d][1,2,3] triazole (ffBTA) with thiophene as $\pi$-bridge were designed and synthesized. Two asymmetric-buildingblock-containing polymers (ABC-polymers) possess a strong and broad absorption in the range of 300-750 $\mathrm{nm}$ and medium optical bandgap of 1.73 and $1.77 \mathrm{eV}$ for PDTPa-TBTA and PDTPa-TffBTA, respectively. Polymer solar cells using PDTPa-TBTA as donor and [6,6]-phenyl- $\mathrm{C}_{71}$-butyric acid methyl ester ( $\mathrm{PC}_{71} \mathrm{BM}$ ) as an acceptor exhibited power conversion efficiencies (PCE) of $2.22 \%$ with a $V_{\text {oc }}$ of $0.58 \mathrm{~V}$, a $J_{\text {sc }}$ of $6.04 \mathrm{~mA} / \mathrm{cm}^{2}$, and an FF of $63.41 \%$. The introduction of fluorine substituents on the BTA unit evidently influenced the optical and photovoltaic properties. Interestingly, although the HOMO energy level indeed decreased, PDTPa-TffBTA showed a decreased $V_{\text {oc }}$ of $0.52 \mathrm{~V}$ in solar cells. Combined with an obviously enhanced $J_{\mathrm{sc}}$ of $10.23 \mathrm{~mA} / \mathrm{cm}^{2}$, and an outstanding FF of 0.64 , the PCE of solar cells based on PDTPa-TffBTA was improved by nearly 55\%, reached $3.43 \%$. Our results indicate that the BTA unit can be used to construct $\mathrm{ABC}$ polymers with a medium bandgap, and the introduction of fluorine on the BTA unit is also effective in improving the photovoltaic performance.
\end{abstract}

Keywords: polymer solar cells; asymmetrical building blocks; dithienopyran (DTPa); benzotriazole (BTA)

\section{Introduction}

Over the past few decades, polymer solar cells (PSCs), given the advantages of a low cost, a light weight, and flexibility, have attracted extensive attention for the generation of affordable, clean, and renewable energy [1]. Generally, efficient PSCs adopt a bulk heterojunction device structure, utilizing a p-type conjugated polymer as a donor and an n-type material (fullerene derivatives, conjugated polymers, or small molecules) as an acceptor [2-9]. Traditionally, from the knowledge of some classic donor polymer system, such as poly(3-hexylthiophene-2,5-diyl) (P3HT) [10-13], people have believed that photovoltaic polymers with great promise should be region-regular, so symmetric building blocks have played a dominant role in the design and synthesis of D-A (donor-acceptor) type polymer photovoltaic materials. However, some effective asymmetrical building blocks have developed gradually to construct promising photovoltaic polymers, such as poly [[4,8-bis-[(2-ethylhexyl)oxy]benzo[1,2-b:4,5-b']dithiophene-2,6-diyl][3-fluoro-2[(2-ethylhexyl)carbonyl]thieno[3,4-b]thiophene-4,6-diyl]] (PTB7) and its analogues, with the best power conversion efficiency over 10\% [14-16]. This made people realize that the lack of enough attention 
restricted the development of asymmetric-building-block-containing polymers (ABC polymers) [17]. Consequently, it has become very important to develop new asymmetrical building blocks and explore the relationship between photovoltaic performance and structures of $\mathrm{ABC}$ polymers.

On the other hand, in our previous research, we found that the characters of copolymers such as the frontier molecular orbital, the architecture of the molecule, and the optoelectronic properties could be significantly influenced by the $\pi$-bridge units. However, there is still an extreme lack of research on the effect of $\pi$-bridges on the properties of ABC polymers. Recently, we designed and synthesized conjugated polymers based on asymmetric dithieno[3,2-b:2', $3^{\prime}$-d]pyran (DTPa) donor and benzothiadiazole (BT) acceptors and shown in Scheme 1 [17,18]. When inserting a thiophene bridge between these two segments, the forming polymers suffer from poor solubility in common organic solvents. Therefore, we had to introduce hexyl substituents in the thiophene bridge to guarantee the solubility of the polymers for preparation and purification, as well as exploration of the properties of the polymer semiconductors in solution-processable photovoltaic devices. However, steric hindrance of the alkyl substituents led to an obvious increase in dihedral angles between the thiophene bridge and the DTPa unit and consequently affected the conjugation of the resulting polymers.

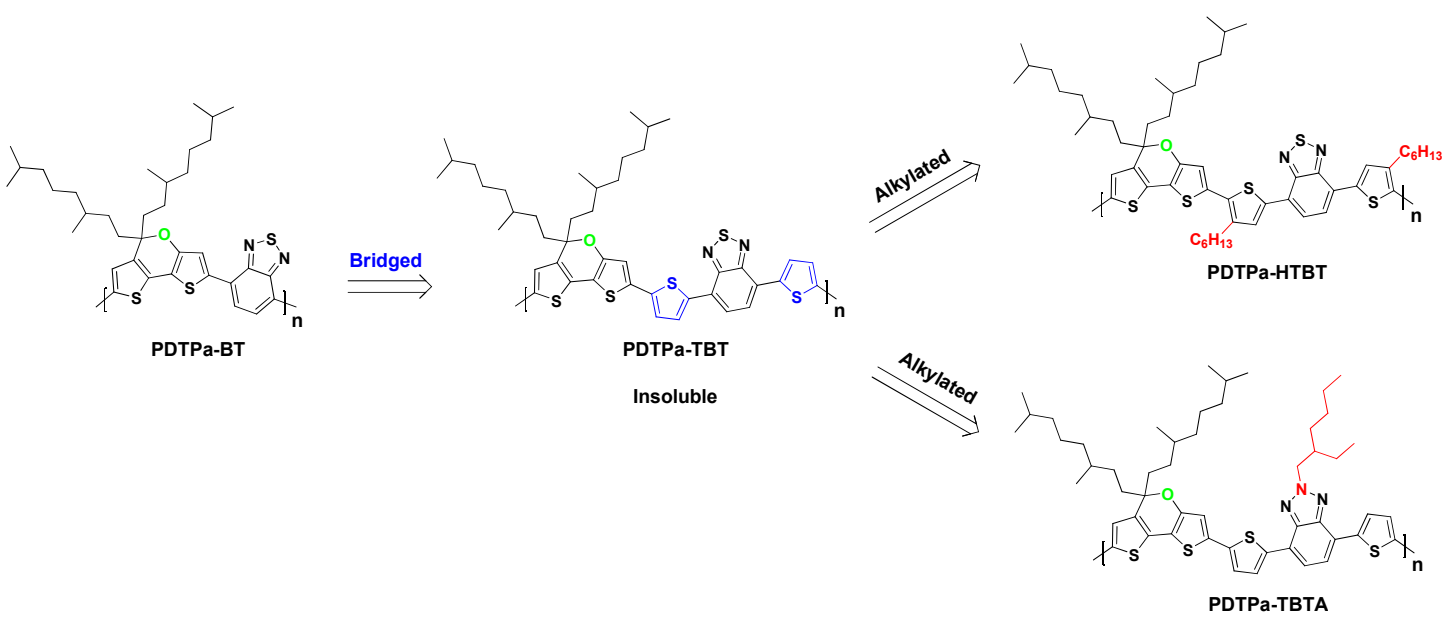

Scheme 1. The chemical structures of the polymers based on DTPa, BT, and BTA.

In order to solve this problem, benzo[d][1-3]triazole (BTA) was used instead of the BT acceptor. Among large amounts of electron-deficient building blocks, benzotriazole is one of the most widely used and excellent acceptors. Besides p-type polymers, BTA is also effective in constructing small non-fullerene molecules $[19,20]$. Compared to the analogue benzothiadiazole derivatives (BTs), BTA-based polymers provide the prominent advantage of facile incorporation of solubilizing alkyl chains onto the acceptor unit, rather than on the thiophene $\pi$-bridge. Therefore, placing the alkyl chain away from the polymer backbone on the BTA unit allows the polymer backbone to adopt a more planar conformation [21]. Thus, BTA-based D-A type polymers, combined with the electron-donating group of benzodithiophene [22-27], dithienylsilole [28], fluorene, phenylene, and carbazole [29], have been investigated in the past few years. However, BTA has not been copolymerized with asymmetric electron-donating building blocks. Therefore, in this work, we designed and synthesized D- $\pi$-A conjugated polymers combining asymmetric DTPa donor and BTA or BTA fluorinate acceptors, bridged by thiophene, to explore the effect of the symmetry and fluorination on the performance of photovoltaic polymers. The structures and synthetic routes of the polymers are shown in Scheme 2. 


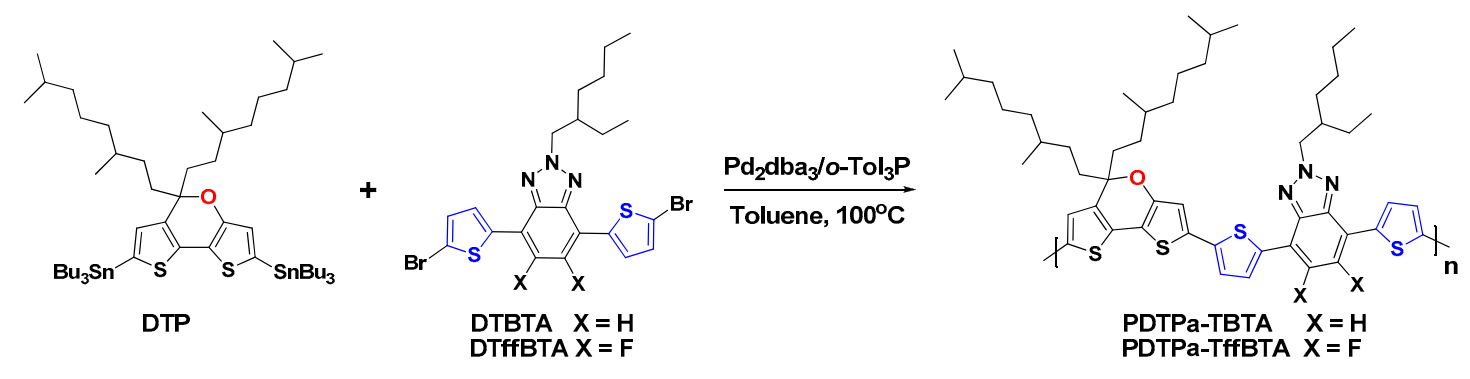

Scheme 2. Chemical structures and synthetic routes of PDTPa-TBTA and PDTPa-TffBTA.

\section{Experimental Section}

\subsection{Measurements and Characterization}

The molecular weights of the polymers were measured via the gel permeation chromatography (GPC) method. The number-average molecular weights $\left(M_{n}\right)$, weight-average molecular weights $\left(M_{\mathrm{W}}\right)$, and polydispersity index (PDI, $M_{\mathrm{W}} / M_{\mathrm{n}}$ ) were measured on a PL-220 (Polymer Laboratories Ltd., Shropshire, UK) chromatography connected to a differential refractometer with polystyrene as a reference standard and 1,2,4-trichlorobenzene as an eluent (at $150{ }^{\circ} \mathrm{C}$ ). Elemental analyses were performed on a Flash EA 1112 analyzer (Thermo Electron Corporation, Waltham, MA, USA). Absorption spectra measurements of the polymers were carried out in a chloroform solution and films at room temperature, recorded on a Hitachi UH5300 spectrophotometer (Hitachi High-Technologies Corporation, Tokyo, Japan). The electrochemical cyclic voltammetry was performed on a Shanghai Chenhua CHI620 electrochemical workstation, with a platinum plate, an $\mathrm{Ag} / \mathrm{AgCl}$ electrode, and a platinum wire as the working electrode, the reference electrode, and the counter electrode, respectively, in a $0.1 \mathrm{~mol} / \mathrm{L}$ tetrabutyl ammonium hexafluorophosphate $\left(\mathrm{Bu}_{4} \mathrm{NPF}_{6}\right)$ acetonitrile solution. Polymer thin films were formed by drop-casting of polymer solutions in $\mathrm{CHCl}_{3}$ on the working electrode and then dried in air.

\subsection{Fabrication of the Photovoltaic Devices}

Organic solar cells were fabricated with the typical sandwich structure of ITO/PEDOT:PSS/active layer/Ca/Al. The tin-doped indium oxide (ITO) glass substrate as a positive electrode, $\mathrm{Ca} / \mathrm{Al}$ metal electrode was evaporated as a cathelectrode, and the blend film of the polymer $/ \mathrm{PC}_{71} \mathrm{BM}$ located as an active layer. Glass substrates coated with patterned ITO were cleaned by ultrasonication in detergent, water, acetone, and 2-propanol. Then, under a stream of nitrogen and subjected to the treatment of UV-Ozone for $15 \mathrm{~min}$ after drying. And coated by a thin layer of poly(3,4-ethylene dioxythiophene):poly(styrenesulfonate) (PEDOT:PSS), which was spin-coated from a PEDOT:PSS aqueous solution on the ITO substrate at a speed of $3000 \mathrm{rpm} / \mathrm{s}$ and annealed at $150{ }^{\circ} \mathrm{C}$ for $15 \mathrm{~min}$ in air atmosphere. The photosensitive layer was prepared by spin-coating a blend solution of polymer and $\mathrm{PC}_{71} \mathrm{BM}$ (1:1.5 or 1:2, by weight) in $o$-dichlorobenzene (DCB), at a concentration of $10 \mathrm{mg} \mathrm{mL}^{-1}$ for polymer. Then, the cathode (the calcium layer about $20 \mathrm{~nm}$, the aluminum layer about $100 \mathrm{~nm}$ ) was deposited on the polymer layer. The thickness of the active layer was ca. $100 \mathrm{~nm}$, measured with an Ambios Tech XP-2 profilmeter. The effective area of one cell was ca. $4 \mathrm{~mm}^{2}$. The J-V curve was measured using a Keithley 236 source measure unit. Photocurrent was measured with a solar simulator with an AM 1.5 filter at $100 \mathrm{~mW} \mathrm{~cm}^{-2}$ was used as the white-light source.

\subsection{Synthesis of the Polymers}

The synthesis of the polymers was carried out using palladium-catalyzed Stille-coupling between monomer 4,7-bis(5-bromothiophen-2-yl)-2-(2-ethylhexyl)-2H-benzo[d][1-3]-triazole derivatives (1 eq) and DTPa-distannyl (1.02 eq), as shown in Scheme 2. Monomers were dissolved in toluene, then $\mathrm{Pd}_{2}(\mathrm{dba})_{3}(2.5 \%$ in $\mathrm{mol})$ and $(o-\mathrm{tol})_{3} \mathrm{P}(20 \%$ in mol $)$ were added to the reaction vial with a 
magnetic stirring bar. After being purged by three freeze-pump-thaw cycles, the mixture was heated for $24 \mathrm{~h}$ at $100{ }^{\circ} \mathrm{C}$. Then, to the reaction mixture, bromobenzene ( $\left.5 \mathrm{eq}\right)$ was added as end-cappers and stirred for another $6 \mathrm{~h}$. After the reaction was cooled to room temperature, the reaction mixture was added dropwise to $120 \mathrm{~mL}$ of ethanol. The precipitate was extracted successively by methanol, hexane, chloroform, and chlorobenzene using a Soxhlet extractor. Then, chromatography was performed to further purify the polymers. After the standard operation, the products were dried in a vacuum oven overnight to yield the titled polymer.

PDTPa-TBTA. Yield: $68 \% ; M_{\mathrm{n}}=24.6 \mathrm{kDa}, M_{\mathrm{w}}=56.6 \mathrm{kDa}$, PDI $=2.3$; Anal. Calcd for $\left(\mathrm{C}_{55} \mathrm{H}_{74} \mathrm{~N}_{2} \mathrm{OS}_{5}\right)_{\mathrm{n}}: \mathrm{C}, 70.70 ; \mathrm{H}, 7.79 ; \mathrm{N}, 4.85$. Found: $\mathrm{C}, 70.86 ; \mathrm{H}, 7.89 ; \mathrm{N}, 4.78$.

PDTPa-TffBTA. Yield: $66 \% ; M_{\mathrm{n}}=28.4 \mathrm{kDa}, M_{\mathrm{w}}=51.1 \mathrm{kDa}$, PDI $=1.8$; Anal. Calcd for $\left(\mathrm{C}_{55} \mathrm{H}_{73} \mathrm{FN}_{2} \mathrm{OS}_{5}\right)_{\mathrm{n}}$ : C, 67.88; H, 7.26; N, 4.66. Found: $\mathrm{C}, 68.01 ; \mathrm{H}, 7.38 ; \mathrm{N}, 4.58$.

\section{Results and Discussion}

\subsection{Optical and Electronic Properties}

Absorption spectra of the polymer PDTPa-TBTA and PDTPa-TffBTA in a dilute chloroform solution and as spin-coated thin films are shown in Figure 1. The detailed absorption data, including the absorption maxima $\left(\lambda_{\text {abs }}\right)$ in solution and film, as well as the corresponding absorption edge (onset, $\left.\lambda_{\text {onset }}\right)$ and band gaps $\left(E_{\mathrm{g}}{ }^{\text {opt }}\right)$, are presented in Table 1 .

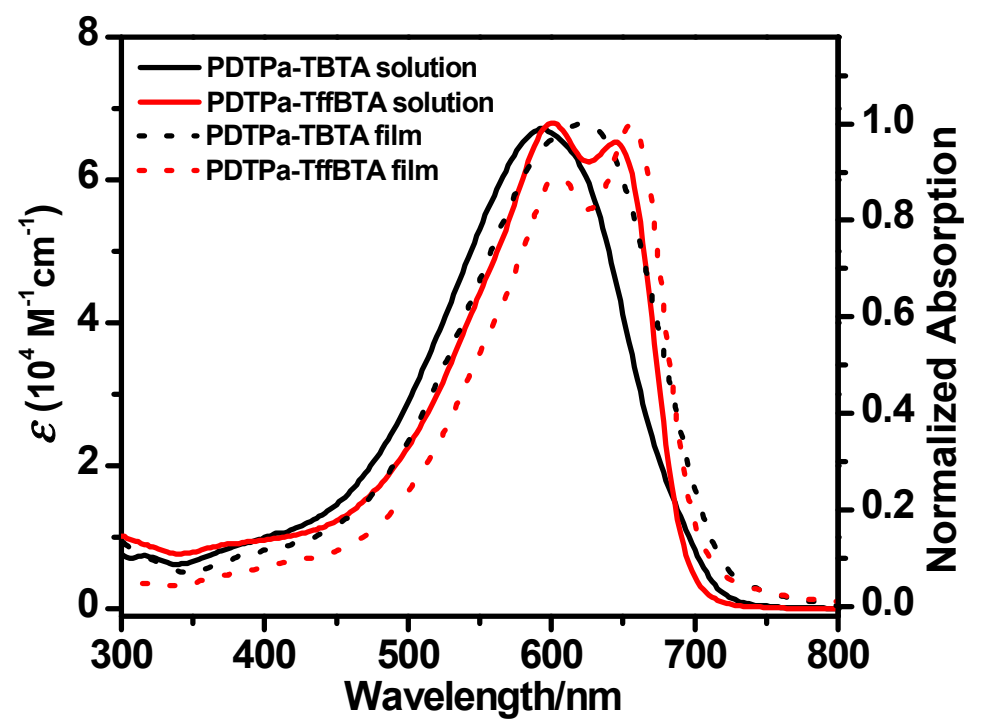

Figure 1. Absorption spectra of PDTPa-TBTA and PDTPa-TffBTA in a dilute chloroform solution and as thin films.

Both of the absorption spectra recorded from dilute chloroform solutions feature a single absorption peak. The molar extinction coefficient $(\varepsilon)$ of the polymer PDTPa-TBTA is $6.7 \times 10^{4} \mathrm{M}^{-1}$ $\mathrm{cm}^{-1}$ in chloroform. Compared to that of PDTPa-TBTA in solution, the absorption spectrum in film is redshifted in the absorption maximum, from 593 to $622 \mathrm{~nm}$. While the onset wavelength of the absorption spectra locate at around $715 \mathrm{~nm}$, almost the same in solution and film, corresponding to a medium bandgap of $1.73 \mathrm{eV}$.

The fluorinated polymer PDTPa-TffBTA show clear signs of aggregation even in solution, with an absorption peak at $601 \mathrm{~nm}$ and a well-marked vibronic shoulder at $645 \mathrm{~nm}$. The fluorination slightly improves the molar extinction coefficient of PDTPa-TffBTA to $6.8 \times 10^{4} \mathrm{M}^{-1} \mathrm{~cm}^{-1}$. In a solid film, the shoulder peak is enhanced to be the absorption maximum, indicating strong intermolecular interactions existing in the solid state. At the same time, the absorption peaks bathochromic shift in film, from 601 and $645 \mathrm{~nm}$ to 604 and $656 \mathrm{~nm}$, respectively, compared with those in the solution. 
The onset wavelength is redshifted from 692 to $700 \mathrm{~nm}$, corresponding to a bandgap of 1.79 and $1.77 \mathrm{eV}$. In addition, the introduction of fluorine in benzotriazole causes a redshift of the absorption maximum and a blueshift in the absorption edge (onset wavelength) of the absorption spectra in both the solution and solid films.

Table 1. Optical properties and experimental and calculated band gaps of the DTPa-based polymers.

\begin{tabular}{ccccc}
\hline Polymer & $\lambda_{\text {abs }}$ in $\mathrm{CHCl}_{3}(\mathbf{n m})$ & $\lambda_{\text {abs }}$ in Films $(\mathbf{n m})$ & $\lambda_{\text {onset }}$ in Films $(\mathbf{n m})$ & $E_{\mathbf{g}}$ opt $(\mathrm{eV})$ \\
\hline PDTPa-TBTA & 593 & 622 & 715 & 1.73 \\
PDTPa-TffBTA & 601,645 & 604,656 & 700 & 1.77 \\
\hline
\end{tabular}

Energy levels of the highest occupied molecular orbital (HOMO), the lowest unoccupied molecular orbital (LUMO) energy levels (vs. vacuum) of the polymers were determined from the onset oxidation $\left(E_{\mathrm{OX}}\right)$ and reduction potentials $\left(E_{\mathrm{red}}\right)$ in the cycle voltammogram, which correspond to the ionization potential (IP) and electron affinity (EA), respectively. Cycle voltammograms of the polymer films and standard substance ferrocene are shown in Figure 2a. The HOMO and LUMO energy levels and electrochemical band gaps $\left(E_{\mathrm{g}}{ }^{\mathrm{CV}}\right)$ of the polymers are calculated and summarized in Table 2 . The onset oxidation and reduction potential of PDTPa-TBTA are 0.56 and $-1.45 \mathrm{~V}$ vs. Ag/ AgCl, corresponding to $\mathrm{HOMO}$ and LUMO energy levels of -4.88 and $-2.87 \mathrm{eV}$, respectively. The introduction of fluorine atoms on the BTA unit slightly decreases the HOMO energy levels of the polymer PDTPa-TffBTA to $-4.93 \mathrm{eV}$. While the LUMO energy level of PDTPa-TffBTA is decreased to $-2.97 \mathrm{eV}$. The lower HOMO levels of PDTPa-TffBTA should result in better oxidative stability in ambient conditions and be propitious to achieve a higher open-circuit voltage $\left(V_{\mathrm{oc}}\right)$ in photovoltaic devices.
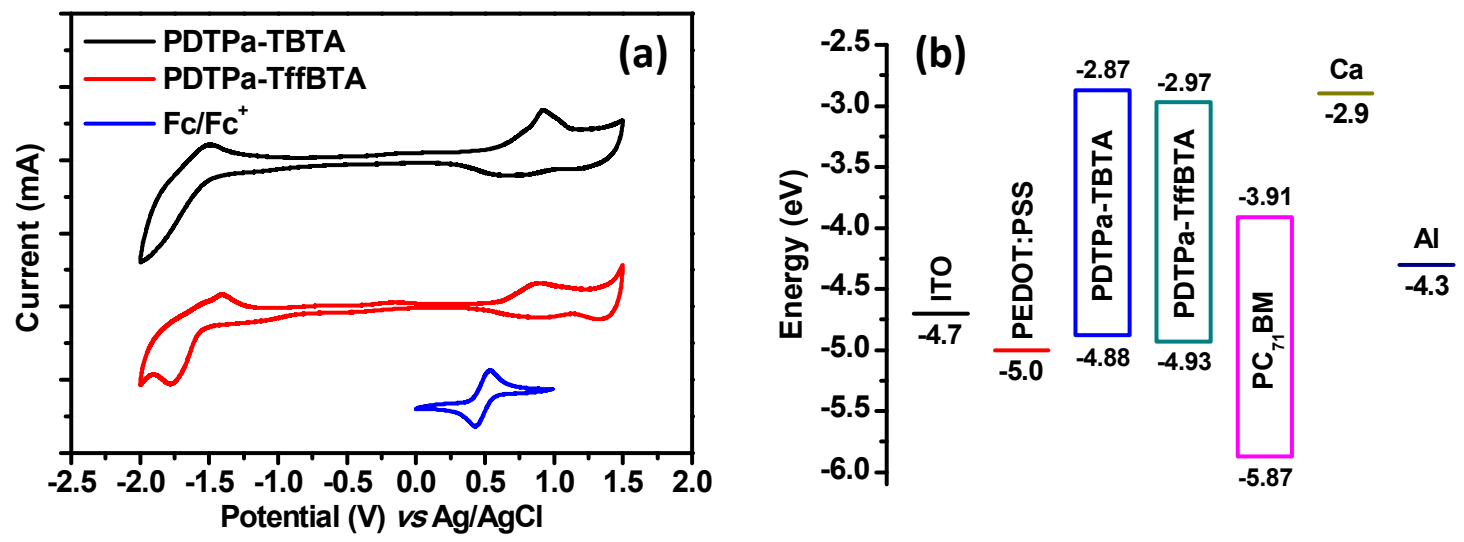

Figure 2. (a) Cyclic voltammograms of the polymer films on Pt electrode in $0.1 \mathrm{~mol} \mathrm{~L}^{-1} \mathrm{Bu}_{4} \mathrm{NPF}_{6}$, $\mathrm{CH}_{3} \mathrm{CN}$ solution with a scan rate of $100 \mathrm{mV} \mathrm{s}^{-1}$. (b) Energy levels with respect to the vacuum of the materials used in the photovoltaic cells.

Table 2. Electrochemical properties of the DTPa-based polymers.

\begin{tabular}{cccccc}
\hline Polymer & $E_{\mathrm{Ox}}(\mathrm{V})$ & HOMO $(\mathrm{eV})$ & $E_{\text {red }}(\mathrm{V})$ & LUMO $(\mathrm{eV})$ & $E_{\mathrm{g}} \mathrm{CV}(\mathrm{eV})$ \\
\hline PDTPa-TBTA & 0.56 & -4.88 & -1.45 & -2.87 & 1.96 \\
PDTPa-TffBTA & 0.61 & -4.93 & -1.55 & -2.97 & 2.01 \\
\hline
\end{tabular}

\subsection{Photovoltaic Properties}

To investigate the effect of fluorination on the photovoltaic performance of the asymmetric-building-block-based polymers, bulk heterojunction polymer solar cells were fabricated. Energy levels with respect to the vacuum of the materials used in the photovoltaic cells are shown in Figure 2b. Figure 3a shows the current density $(J)$-potential $(V)$ characteristic of PSCs based on the 


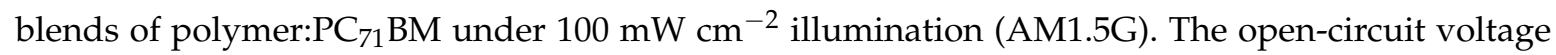
$\left(V_{\mathrm{oc}}\right)$, the short-circuit current $\left(J_{\mathrm{sc}}\right)$, the fill factor $(\mathrm{FF})$, the power conversion efficiency (PCE), and the hole mobility $\left(\mu_{\mathrm{h}}\right)$ of the PSCs are summarized in Table 3.
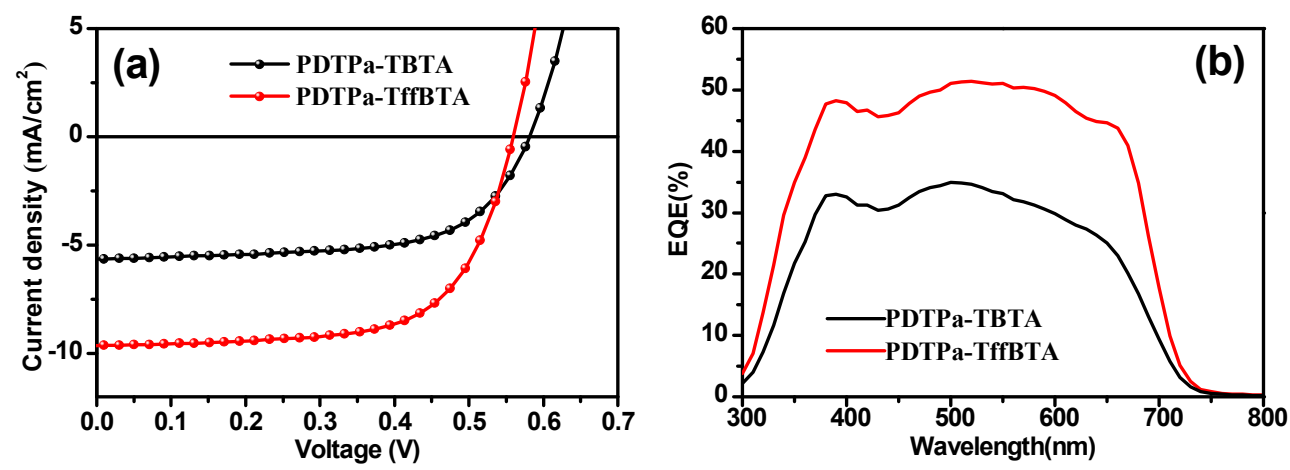

Figure 3. Performance of PSCs under simulated $100 \mathrm{~mW} \mathrm{~cm}{ }^{-2}$ AM1.5G illumination. $J-V$ curves (a) and EQE spectra (b) of the devices ITO/PEDOT:PSS/PDTPa-TBTA: PC $_{71}$ BM $(1: 1.5, w / w)$ or PDTPa-TffBTA: PC 71 BM $(1: 2, w / w) / C a(20 \mathrm{~nm}) / \mathrm{Al}(100 \mathrm{~nm})$.

Table 3. Photovoltaic performance of PSCs with the device structure of ITO/PEDOT:PSS/ PDTPa-TBTA: PC 71 BM $(1: 1.5, w / w)$ or PDTPa-TffBTA: PC 71 BM $(1: 2, w / w) / C a(20 \mathrm{~nm}) / \mathrm{Ag}(100 \mathrm{~nm})$.

\begin{tabular}{|c|c|c|c|c|c|}
\hline Polymer & $V_{\mathrm{oc}}[\mathrm{v}]$ & $J_{\mathrm{sc}}\left[\mathrm{mA} \mathrm{cm}^{-2}\right]$ & FF & $\mathrm{PCE}_{\max }\left(\mathrm{PCE}_{\text {ave }}{ }^{\mathrm{a}}\right)[\%]$ & Hole Mobility ${ }^{b}\left[\mathrm{~cm}^{2} \mathrm{v}^{-1} \mathrm{~s}^{-1}\right]$ \\
\hline РDTPa-TBTA & 0.58 & 6.04 & 0.63 & $2.22(2.17)$ & $1.61 \times 10^{-5}$ \\
\hline РDTPa-TffBTA & 0.52 & 10.23 & 0.64 & $3.43(3.20)$ & $2.66 \times 10^{-4}$ \\
\hline
\end{tabular}

a The average PCE is obtained from over 10 devices. ${ }^{\mathrm{b}}$ Measured via a space charge limited current (SCLC) method.

In most cases, the introduction of the electron-withdrawing fluorine atom on polymers will lower $\mathrm{HOMO}$ energy levels of the resulting polymers and consequently increase the $V_{\mathrm{oc}}$ of the corresponding solar cells [30-32]. Surprisingly, it is found that, with the substitution of fluorine atom on the BTA unit, the $V_{\text {oc }}$ of the devices decreased from $0.58 \mathrm{~V}$ for PDTPa-TBTA to $0.52 \mathrm{~V}$ for PDTPa-TffBTA-based PSCs, although the HOMO energy level indeed decreased. A similar abnormal phenomenon has been also found in several benzothiadiazole-based polymer solar cells [33-38], and the discrepancy was explained in terms of the morphology of the blended active layer. The PDTPa-TBTA gives a PCE of $2.22 \%$, with a $J_{\mathrm{sc}}$ of $6.04 \mathrm{~mA} \mathrm{~cm}^{-2}$ and an FF of 0.63 without thermal annealing treatment. For the fluorine substituted polymer, PDTPa-TffBTA showed higher PCE of 3.43\%, an FF of 0.64 and a significantly increased $J_{\mathrm{sc}}$ of $10.23 \mathrm{~mA} \mathrm{~cm}^{-2}$.

In order to investigate the effect of fluorination of the polymers on the morphologies and microstructures of the active layers of the PSCs, tapping-mode atom force microscopy (AFM) was employed to analyze active layers of the polymer solar cells. As shown in Figure 4, PDTPa-TBTA:PC ${ }_{71}$ BM film displayed very smooth and uniform surface with a root-mean-square (RMS) of $0.99 \mathrm{~nm}$. The introduction of fluorine on BTA made the phase separate clearly in the PDTPa-TffBTA:PC ${ }_{71} \mathrm{BM}$ blend with an increased RMS of $2.14 \mathrm{~nm}$, indicating an increase of aggregation domain size in the blend. The enlargement in the aggregation domain size of the active layer could be beneficial to the charge carrier transport in the bulk heterojunction (BHJ) active layers. The law is in accordance with the effect of fluorination of most photovoltaic polymers in previous reports $[16,17,29-31]$. However, the morphology of the active layers was inadequate to explain the discrepancy in the $V_{\text {oc }}$ of solar cells based on the DTPa-BTA copolymers. As discussed in our previous work, there might be additional energy loss $\left(V_{\text {oc }}\right.$ loss) in some BHJ photovoltaic materials system [39]. Due to the complexity of influencing factors of $V_{\text {oc }}[40]$, the reason for the discrepancy that fluorination of the donor polymer decreased open-circuit voltage of corresponding solar cells is still unclear and needs further study. 

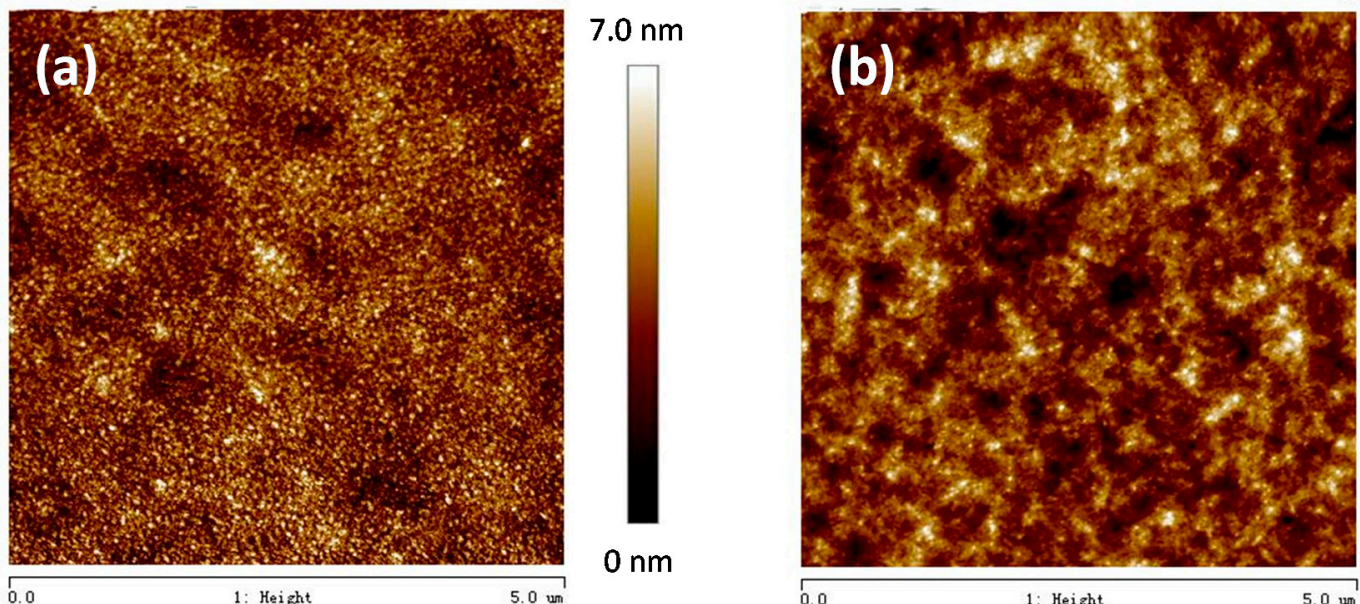

$15.0 \mathrm{~nm}$

Figure 4. AFM height image of (a) PDTPa-TBTA:PC 71 BM $(1: 1.5, w / w)$ and (b) PDTPa-TffBTA: PC 71 BM $(1: 2, w / w)$ active layers.

The photovoltaic properties of the polymers could be further investigated by the external quantum efficiency (EQE) spectra of the devices. Both polymers show broad photo response from 300 to nearly $750 \mathrm{~nm}$, and the flat EQE values, as shown in Figure $3 \mathrm{~b}$, indicate the balanced contribution from the polymers and acceptor PC ${ }_{71}$ BM in both of PDTPa-BTA- and PDTPa-ffBTA-based devices. The significant increase in the EQE value proves more efficient photon harvesting and charge collection in the PDTPa-TffBTA-based active layers, than that of PDTPa-TBTA.

To further understand the difference device performance between PDTPa-TBTA and PDTPa-TffBTA, the charge transport properties of the active layers (polymer:PC ${ }_{71}$ BM blends) were investigated using the space charge limited current (SCLC) method with the hole only device with a configuration of ITO/PEDOT:PSS/polymer:PC ${ }_{71} \mathrm{BM} / \mathrm{Au}$. The experimental dark current densities of the polymer:PC ${ }_{71} \mathrm{BM}$ blends were measured when applied with voltage from -5 to $5 \mathrm{~V}$. The applied voltage was corrected from the voltage drop $V_{\text {rs }}$ due to the series resistance and contact resistance from ITO/PEDOT:PSS, which were measured to be about $35 \Omega$ from a reference device without the layer of polymer:PC ${ }_{71} \mathrm{BM}$. From the plots of $J^{0.5}$ vs. $V$, the hole mobilities of the polymers were deduced from the Mott-Gurneys law [41]:

$$
J=\frac{9}{8} \varepsilon_{\mathrm{r}} \varepsilon_{0} \mu_{\mathrm{h}} \frac{V^{2}}{L^{3}}
$$

where $\varepsilon_{\mathrm{r}}$ is the dielectric constant of the polymer, which is assumed to be around $3, \varepsilon_{0}$ is the permittivity of free space, $\mu_{\mathrm{h}}$ is the hole mobility, $V$ is the voltage drop across the device, and $L$ is the film thickness of the active layer. The plots of the current density vs. voltage for the devices are shown in Figure 5. The hole mobility of PDTPa-TffBTA/PC 71 BM film are calculated to be $2.66 \times 10^{-4} \mathrm{~cm}^{2} \mathrm{v}^{-1} \mathrm{~s}^{-1}$, which is much higher than that of PDTPa-TBTA/PC 71 BM of $1.61 \times 10^{-5} \mathrm{~cm}^{2} \mathrm{v}^{-1} \mathrm{~s}^{-1}$. Apparently, charge carrier mobilities were increased for extent and which is one important reason for their $J_{\mathrm{sc}}$ and high PCE values. Besides the optical properties, the increase in charge carrier mobilities should be another important reason for the obvious promotion of $J_{\mathrm{sc}}$ and PCE values in PDTPa-TffBTA-based solar cells, compared to those of PDTPa-TBTA. 


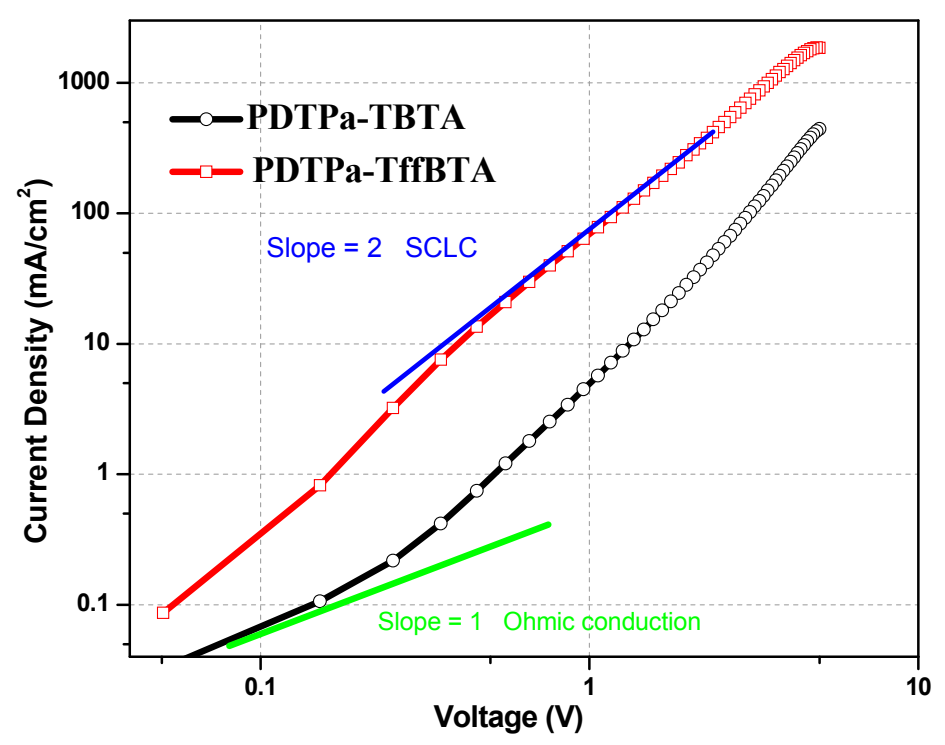

Figure 5. Typical $J-V$ curves based on the hole-only devices of ITO/PEDOT:PSS/active layer/Au.

\section{Conclusions}

In summary, two new conjugated polymers with $5 H$-dithieno[3,2-b:2', $3^{\prime}$-d]pyran (DTPa) as an electron donor and benzo[d][1-3]triazole (BTA) or di-fluorinated benzo[d][1-3] triazole (ffBTA) as an electron acceptor with thiophene as a $\pi$-bridge were synthesized and characterized. To the best of our knowledge, it is the first time to copolymerize BTA with asymmetric electron-donating building blocks. Two asymmetric-building-block-containing polymers (ABC-polymers) possess strong and broad absorption in the range of 300-750 nm and a medium optical bandgap of 1.73 and $1.77 \mathrm{eV}$ for PDTPa-TBTA and PDTPa-TffBTA, respectively. With the introduction of fluorine on the BTA unit, the absorption peaks redshift and obvious shoulder peak appear, indicating strong intermolecular interactions existing in the fluorinated polymer system. Interestingly, although the HOMO energy level indeed decreased, the fluorination decreased the $V_{\text {oc }}$ of $\mathrm{ABC}$ polymers from $0.58 \mathrm{~V}$ for PDTPa-TBTA to $0.52 \mathrm{~V}$ for PDTPa-TffBTA. At the same time, the introduction of fluorine on the BTA unit remarkably improved $J_{\mathrm{sc}}$ of the solar cells based on the resulting polymer by nearly $70 \%$. Together with an outstanding FF of 0.64 , fluorination increased the PCE of the solar cells by nearly $55 \%$, from $2.22 \%$ for that of PDTPa-TBTA to $3.43 \%$ for that of PDTPa-TffBTA. These results indicate that the introduction of fluorine on the BTA unit is also effective in improving the photovoltaic performance of $A B C$ polymers.

Acknowledgments: This work was supported by the Natural Science Foundation of China (NSFC, Nos. 21504019, 51673048, 51773046 and 51473040), the Scientific Research Foundation for the Returned Overseas Chinese Scholars, State Education Ministry, the Key Research Program of Frontier Sciences, Chinese Academy of Sciences (Grant No. QYZDB-SSW-SLH033), and the CAS Key Laboratory of Nanosystem and Hierarchical Fabrication.

Author Contributions: Xiaochen Wang and Erjun Zhou designed the experiments; Junyi Hu, Xiaochen Wang, Fan Chen, Bo Xiao, and Ailing Tang performed the experimental works. Junyi Hu, Xiaochen Wang, and Erjun Zhou analyzed the experimental data and wrote the manuscript. Erjun Zhou directed and supervised the research works.

Conflicts of Interest: The authors declare no conflict of interest.

\section{References}

1. Yu, G.; Gao, J.; Hummelen, J.C.; Wudl, F.; Heeger, A.J. Polymer Photovoltaic Cells: Enhanced Efficiencies via a Network of Internal Donor-Acceptor Heterojunctions. Science 1995, 270, 1789-1791. [CrossRef]

2. Thompson, B.C.; Frechet, J.M. Polymer-fullerene composite solar cells. Angew. Chem. Int. Ed. Engl. 2008, 47, 58-77. [CrossRef] [PubMed]

3. Li, G.; Zhu, R.; Yang, Y. Polymer solar cells. Nat. Photonics 2012, 153-161. [CrossRef] 
4. Huang, Y.; Kramer, E.J.; Heeger, A.J.; Bazan, G.C. Bulk Heterojunction Solar Cells: Morphology and Performance Relationships. Chem. Rev. 2014, 114, 7006-7043. [CrossRef] [PubMed]

5. Cheng, Y.J.; Yang, S.H.; Hsu, C.S. Synthesis of Conjugated Polymers for Organic Solar Cell Applications. Chem. Rev. 2009, 109, 5868-5923. [CrossRef] [PubMed]

6. Li, C.; Liu, M.Y.; Pschirer, N.G.; Baumgarten, M.; Mullen, K. Polyphenylene-Based Materials for Organic Photovoltaics. Chem. Rev. 2010, 110, 6817-6855. [CrossRef] [PubMed]

7. Zhang, S.; Ye, L.; Hou, J. Breaking the 10\% Efficiency Barrier in Organic Photovoltaics: Morphology and Device Optimization of Well-Known PBDTTT Polymers. Adv. Energy Mater. 2016, 6, 1502529. [CrossRef]

8. Li, H.; He, D.; Mao, P.; Wei, Y.; Ding, L.; Wang, J. Additive-Free Organic Solar Cells with Power Conversion Efficiency over 10\%. Adv. Energy Mater. 2017, 7, 1602663. [CrossRef]

9. He, Z.; Xiao, B.; Liu, F.; Wu, H.; Yang, Y.; Xiao, S.; Wang, C.; Russell, T.P.; Cao, Y. Single-junction polymer solar cells with high efficiency and photovoltage. Nat. Photonics 2015, 9, 174-179. [CrossRef]

10. Osaka, I.; McCullough, R.D. Advances in molecular design and synthesis of regioregular polythiophenes. Acc. Chem. Res. 2008, 41, 1202-1214. [CrossRef] [PubMed]

11. Marrocchi, A.; Lanari, D.; Facchetti, A.; Vaccaro, L. Poly(3-hexylthiophene): Synthetic methodologies and properties in bulk heterojunction solar cells. Energy Environ. Sci. 2012, 5, 8457. [CrossRef]

12. Dang, M.T.; Hirsch, L.; Wantz, G.; Wuest, J.D. Controlling the Morphology and Performance of Bulk Heterojunctions in Solar Cells. Lessons Learned from the Benchmark Poly(3-hexylthiophene): 6,6 -Phenyl-C-61-butyric Acid Methyl Ester System. Chem. Rev. 2013, 113, 3734-3765. [CrossRef] [PubMed]

13. Lei, Y.; Jia, H.; He, W.; Zhang, Y.; Mi, L.; Hou, H.; Zhu, G.; Zheng, Z. Hybrid solar cells with outstanding short-circuit currents based on a room temperature soft-chemical strategy: The case of P3HT:Ag2S. J. Am. Chem. Soc. 2012, 134, 17392-17395. [CrossRef] [PubMed]

14. Liu, C.; Yi, C.; Wang, K.; Yang, Y.; Bhatta, R.S.; Tsige, M.; Xiao, S.; Gong, X. Single-junction polymer solar cells with over $10 \%$ efficiency by a novel two-dimensional donor-acceptor conjugated copolymer. ACS Appl. Mater. Interfaces 2015, 7, 4928-4935. [CrossRef] [PubMed]

15. Liang, Y.; Xu, Z.; Xia, J.; Tsai, S.T.; Wu, Y.; Li, G.; Ray, C.; Yu, L. For the bright future-bulk heterojunction polymer solar cells with power conversion efficiency of 7.4\%. Adv. Mater. 2010, 22, E135-E138. [CrossRef] [PubMed]

16. Das, S.; Keum, J.K.; Browning, J.F.; Gu, G.; Yang, B.; Dyck, O.; Do, C.; Chen, W.; Chen, J.; Ivanov, I.N.; et al. Correlating high power conversion efficiency of PTB7:PC71BM inverted organic solar cells with nanoscale structures. Nanoscale 2015, 7, 15576-15583. [CrossRef] [PubMed]

17. Wang, X.; Tang, A.; Chen, F.; Zhou, E. The effect of conjugated $\pi$-bridge and fluorination on the properties of asymmetric-building-block-containing polymers (ABC polymers) based on dithienopyran donor and benzothiadiazole acceptors. Polym. Chem. 2017, 8, 5396-5406. [CrossRef]

18. Wang, X.; Tang, A.; Chen, Y.; Mahmood, A.; Hou, J.; Wei, Z.; Zhou, E. Effect of fluorination and symmetry on the properties of polymeric photovoltaic materials based on an asymmetric building block. RSC Adv. 2016, 6, 90051-90060. [CrossRef]

19. Xiao, B.; Tang, A.; Zhang, J.; Mahmood, A.; Wei, Z.; Zhou, E. Achievement of high Voc of $1.02 \mathrm{~V}$ for P3HT-based Organic Solar Cell using a Benzotriazole-containing Non-fullerene Acceptor. Adv. Energy Mater. 2017, 7, 1602229. [CrossRef]

20. Xiao, B.; Tang, A.; Yang, J.; Wei, Z.; Zhou, E. P3HT-Based Photovoltaic Cells with a High Voc of 1.22 V by Using a Benzotriazole-Containing Nonfullerene Acceptor End-Capped with Thiazolidine-2,4-dione. ACS Macro. Lett. 2017, 6, 410-414. [CrossRef]

21. Price, S.C.; Stuart, A.C.; Yang, L.; Zhou, H.; You, W. Fluorine substituted conjugated polymer of medium band gap yields 7\% efficiency in polymer-fullerene solar cells. J. Am. Chem Soc. 2011, 133, 4625-4631. [CrossRef] [PubMed]

22. Min, J.; Zhang, Z.-G.; Zhang, S.; Zhang, M.; Zhang, J.; Li, Y. Synthesis and Photovoltaic Properties of D-A Copolymers Based on Dithienosilole and Benzotriazole. Macromolecules 2011, 44, 7632-7638. [CrossRef]

23. Bin, H.; Zhang, Z.G.; Gao, L.; Chen, S.; Zhong, L.; Xue, L.; Yang, C.; Li, Y. Non-Fullerene Polymer Solar Cells Based on Alkylthio and Fluorine Substituted 2D-Conjugated Polymers Reach 9.5\% Efficiency. J. Am. Chem Soc. 2016, 138, 4657-4664. [CrossRef] [PubMed] 
24. Gao, L.; Zhang, Z.G.; Bin, H.; Xue, L.; Yang, Y.; Wang, C.; Liu, F.; Russell, T.P.; Li, Y. High-Efficiency Nonfullerene Polymer Solar Cells with Medium Bandgap Polymer Donor and Narrow Bandgap Organic Semiconductor Acceptor. Adv. Mater. 2016, 28, 8288-8295. [CrossRef] [PubMed]

25. Gao, L.; Zhang, Z.G.; Xue, L.; Min, J.; Zhang, J.; Wei, Z.; Li, Y. All-Polymer Solar Cells Based on Absorption-Complementary Polymer Donor and Acceptor with High Power Conversion Efficiency of 8.27\%. Adv. Mater. 2016, 28, 1884-1890. [CrossRef] [PubMed]

26. Li, Y.; Zhong, L.; Gautam, B.; Bin, H.-J.; Lin, J.-D.; Wu, F.-P.; Zhang, Z.; Jiang, Z.-Q.; Zhang, Z.-G.; Gundogdu, K.; et al. A near-infrared non-fullerene electron acceptor for high performance polymer solar cells. Energy Environ. Sci. 2017, 10, 1610-1620. [CrossRef]

27. Yang, Y.; Zhang, Z.G.; Bin, H.; Chen, S.; Gao, L.; Xue, L.; Yang, C.; Li, Y. Side-Chain Isomerization on an n-type Organic Semiconductor ITIC Acceptor Makes 11.77\% High Efficiency Polymer Solar Cells. J. Am. Chem. Soc. 2016, 138, 15011-15018. [CrossRef] [PubMed]

28. Scott, C.N.; Bisen, M.D.; Stemer, D.M.; McKinnon, S.; Luscombe, C.K. Direct Arylation Polycondensation of 2,5-Dithienylsilole with a Series of Difluorobenzodiimine-Based Electron Acceptors. Macromolecules 2017, 50, 4623-4628. [CrossRef]

29. Zhang, L.; He, C.; Chen, J.; Yuan, P.; Huang, L.; Zhang, C.; Cai, W.; Liu, Z.; Cao, Y. Bulk-Heterojunction Solar Cells with Benzotriazole-Based Copolymers as Electron Donors: Largely Improved Photovoltaic Parameters by Using PFN/Al Bilayer Cathode. Macromolecules 2010, 43, 9771-9778. [CrossRef]

30. Meyer, F. Fluorinated conjugated polymers in organic bulk heterojunction photovoltaic solar cells. Prog. Polym. Sci. 2015, 47, 70-91. [CrossRef]

31. Leclerc, N.; Chávez, P.; Ibraikulov, O.; Heiser, T.; Lévêque, P. Impact of Backbone Fluorination on $\pi$-Conjugated Polymers in Organic Photovoltaic Devices: A Review. Polymers 2016, 8, 11. [CrossRef]

32. Wang, X.; Zhang, Z.-G.; Luo, H.; Chen, S.; Yu, S.; Wang, H.; Li, X.; Yu, G.; Li, Y. Effects of fluorination on the properties of thieno[3,2-b]thiophene-bridged donor- $\pi$-acceptor polymer semiconductors. Polym. Chem. 2014, 5, 502-511. [CrossRef]

33. Schroeder, B.C.; Huang, Z.; Ashraf, R.S.; Smith, J.; D'Angelo, P.; Watkins, S.E.; Anthopoulos, T.D.; Durrant, J.R.; McCulloch, I. Silaindacenodithiophene-Based Low Band Gap Polymers-The Effect of Fluorine Substitution on Device Performances and Film Morphologies. Adv. Funct. Mater. 2012, 22, 1663-1670. [CrossRef]

34. Jo, J.W.; Bae, S.; Liu, F.; Russell, T.P.; Jo, W.H. Comparison of Two D-A Type Polymers with Each Being Fluorinated on D and A Unit for High Performance Solar Cells. Adv. Funct. Mater. 2015, 25, $120-125$. [CrossRef]

35. Cartwright, L.; Iraqi, A.; Zhang, Y.; Wang, T.; Lidzey, D.G. Impact of fluorine substitution upon the photovoltaic properties of benzothiadiazole-fluorene alternate copolymers. RSC Adv. 2015, 5, 46386-46394. [CrossRef]

36. Umeyama, T.; Watanabe, Y.; Douvogianni, E.; Imahori, H. Effect of Fluorine Substitution on Photovoltaic Properties of Benzothiadiazole-Carbazole Alternating Copolymers. J. Phys. Chem. C 2013, 117, 21148-21157. [CrossRef]

37. Li, Z.; Lu, J.; Tse, S.-C.; Zhou, J.; Du, X.; Tao, Y.; Ding, J. Synthesis and applications of difluorobenzothiadiazole based conjugated polymers for organic photovoltaics. J. Mater. Chem. 2011, 21, 3226. [CrossRef]

38. Qi, B.; Wang, J. Open-circuit voltage in organic solar cells. J. Mater. Chem. 2012, 22, 24315. [CrossRef]

39. Wang, X.; Gao, C.; Wang, K.; Fan, X.; Wang, H.; Li, X.; Zhang, Z.-G.; Li, Y. Synthesis and electronic energy-level regulation of imide-fused poly(thienylene vinylene) derivatives. J. Polym. Sci. Part A Chemistry 2013, 51, 4975-4982. [CrossRef]

40. Elumalai, N.K.; Uddin, A. Open circuit voltage of organic solar cells: An in-depth review. Energy Environ. Sci. 2016, 9, 391-410. [CrossRef]

41. Shen, Y.; Hosseini, A.R.; Wong, M.H.; Malliaras, G.G. How to make ohmic contacts to organic semiconductors. Chemphyschem 2004, 5, 16-25. [CrossRef] [PubMed]

(C) 2017 by the authors. Licensee MDPI, Basel, Switzerland. This article is an open access article distributed under the terms and conditions of the Creative Commons Attribution (CC BY) license (http:/ / creativecommons.org/licenses/by/4.0/). 